\title{
Differentiation of European and Far East Asian Populations of Saccharomyces paradoxus by Allozyme Analysis
}

\author{
G. I. NAUMOV ${ }^{1}$ E. S. NAUMOVA ${ }^{1}$ AND P. D. SNIEGOWSKI ${ }^{2 *}$ \\ State Institute for Genetics and Selection of Industrial Microorganisms, 113545 Moscow, Russia, ${ }^{1}$ and \\ Center for Microbial Ecology, Michigan State University, East Lansing, Michigan 48824-1325²
}

\begin{abstract}
Allozyme electrophoresis was used to characterize 39 isolates belonging to the wild yeast species Saccharomyces paradoxus for variation at nine enzyme loci. The data revealed significant genetic differentiation between isolates from two geographically distinct regions, one including continental Europe and the other including the Russian Far East and Japan. The results are consistent with previous observations indicating that there is partial reproductive isolation between isolates collected from these regions, and they suggest the possibility that these two populations represent an early stage in speciation.
\end{abstract}

The evolutionary genetics of yeasts has received little attention compared with the classical and molecular genetics of these organisms, especially as developed in Saccharomyces cerevisiae. Indeed, $S$. cerevisiae is widely regarded as a domesticated organism and is seldom collected away from sources related to human activity, so that studies of wild $S$. cerevisiae populations are problematical. However, at least six sibling species have been identified in the Saccharomyces sensu stricto complex (S. cerevisiae, Saccharomyces paradoxus, Saccharomyces bayanus Hansen, one Brazilian Saccharomyces sp., and two Japanese Saccharomyces spp.) by genetic analysis $(15,18)$ and DNA-DNA reassociation studies $(7,33-35,38)$, and some of these species appear to exist only in the wild state; that is, they are not found in any human baking or fermenting applications. Significantly, classification in the Saccharomyces sensu stricto complex is in accord with the biological species concept (12); interspecific matings yield viable hybrids, but these hybrids produce nonviable ascospores and are consequently sterile. In contrast, the products of intraspecific matings produce highly viable ascospores $(13-15,21,23)$. The existence of interfertile populations of wild Saccharomyces yeasts opens the way to studies of the evolutionary systematics and population genetics of yeasts similar to studies conducted with higher eukaryotes and various other fungi $(27,28,36,37)$. In this paper, we describe a study of genetic variation in wild populations of $S$. paradoxus.

S. paradoxus Batchinskaya (synonyms, S. cerevisiae var. tetrasporus (Beijerinck ex Dekker) Phaff et al., $S$. cerevisiae var. terrestris Jensen, and Saccharomyces douglasii nom. nud. [14, 19]) is the closest relative of S. cerevisiae Hansen. The level of total DNA homology (as determined by reassociation studies) between $S$. cerevisiae and S. paradoxus is approximately $50 \%$. (Some recent studies found considerably higher levels of homology between DNA sequences from individual genetic loci $[1,11])$. The levels of total DNA homology between $S$. cerevisiae and the other sibling species are lower (7, 33-35, 38). While performing genetic identification studies of $S$. paradoxus isolates collected in various regions of the world, we noticed that isolates collected in Europe formed highly fertile hybrids with a reference tester strain of $S$. paradoxus from Denmark, whereas isolates collected from other regions, particularly from the Russian Far East and Japan (referred to as Far East

* Corresponding author. Present address: Department of Biology, Leidy Laboratories, University of Pennsylvania, Philadelphia, PA 19104-6018.
Asia below), showed substantially reduced ascospore viability when they were crossed with the same tester strain $(16,20,23)$. Here we report the results of a biochemical characterization study of 39 S. paradoxus isolates from Europe and Far East Asia in which multilocus enzyme electrophoresis was used. Enzyme electrophoresis has been widely used in population genetic studies of bacteria and higher eucaryotes and in some fungi $(8,36,37,40,41)$, but the method has not yet been used to study natural yeast populations to any appreciable degree. Limited studies of enzyme polymorphism in the Saccharomyces sensu stricto complex have been performed, for the most part, with the cultivated yeast $S$. cerevisiae $(10,32,39)$.

\section{MATERIALS AND METHODS}

Yeast strains. The isolates used and their origins are listed in Table 1. A total of 28 isolates from the European continent (referred to as the EU isolates below) and 11 isolates from Far East Asia (referred to as the FE isolates below) were examined for protein electrophoretic variation. These isolates had been previously assigned to the biological species $S$. paradoxus on the basis of genetic hybridization analysis data. All of the isolates had been maintained as homozygotic homothallic cultures prior to this study.

Preparation of cell lysates for electrophoresis. Overnight cultures grown in 20 $\mathrm{ml}$ of YPD medium at $28^{\circ} \mathrm{C}$ were harvested by centrifugation at $5,000 \times g$ for 10 min, washed once with $1 \mathrm{ml}$ of Tris-glycine buffer $(30 \mathrm{~g}$ of Trizma Base [Sigma] per liter, $144 \mathrm{~g}$ of glycine per liter; $\mathrm{pH} 8.0$ ), resuspended in $0.5 \mathrm{ml}$ of the same buffer, and frozen at $-80^{\circ} \mathrm{C}$. Frozen cell suspensions were thawed and immediately lysed with a sonicator (Heat Systems model W385; Ultrasonics, Inc., Farmingale, N.Y.) at the maximum output for 20 min with continuous cooling at $2^{\circ} \mathrm{C}$ After centrifugation at $4^{\circ} \mathrm{C}$ to remove debris, cell lysates were distributed into chilled Eppendorf tubes in $100-\mu \mathrm{l}$ aliquots and were stored at $-80^{\circ} \mathrm{C}$ until they were used for electrophoresis.

Electrophoresis and gel staining. Enzymes were separated by using the Zip Zone cellulose acetate system (Helena Laboratories, Beaumont, Tex.). For mos enzymes, electrophoresis was carried out at room temperature at $185 \mathrm{~V}$ for 35 min. For arginine kinase (ARK), glucose-6-phosphate dehydrogenase (G6PDH), and malate dehydrogenase (MDH), electrophoresis was carried out at $100 \mathrm{~V}$ for $40 \mathrm{~min}$. Gel staining was performed as described by Hebert and Beaton (5). Only enzymes that produced consistently scoreable, sharp bands were used in the analysis. All enzyme extracts were electrophoretically examined three times and produced consistent zymograms. The following nine enzymes were studied: alcohol dehydrogenase (ADH) (EC 1.1.1.1), ARK (EC 2.7.3.3), G6PDH (EC 1.1.1.49), glucose-6-phosphate isomerase (GPI) (EC 5.3.1.9), isocitrate dehydrogenase (IDH) (EC 1.1.1.42), lactate dehydrogenase (LDH) (EC 1.1.1.27), MDH (EC 1.1.1.37), mannose-6-phosphate isomerase (MPI) (EC 5.3.1.8), and phosphoglucomutase (PGM) (EC 5.4.2.2.). We used side-by-side electrophoretic comparisons to confirm equivalence in enzyme mobilities between isolates. For each enzyme, distinct electromorphs were numbered in order of increasing anodal mobility. The electromorph with the greatest anodal mobility was desig nated electromorph 1 , and the progressively more slowly migrating variants were assigned increasing numbers. Each isolate was characterized by its combination of electromorphs for the nine enzymes.

Data analysis. Population differentiation at individual loci was analyzed by the Fisher exact test. When the data could be represented by a 2-by- 2 table of alleles within populations, the program FISH6 (3) was used to obtain a probability value for the table. When more than two alleles were observed at a locus, the program 
TABLE 1. Wild isolates of $S$. paradoxus used in this study

\begin{tabular}{|c|c|c|c|c|c|}
\hline \multicolumn{2}{|c|}{ Strain designation ${ }^{a}$} & \multirow{2}{*}{ Source } & \multirow{2}{*}{ Geographical origin } & \multirow{2}{*}{ Reference } & \multirow{2}{*}{ ET } \\
\hline Original & ATCC & & & & \\
\hline \multicolumn{6}{|l|}{ EU isolates } \\
\hline CBS 406 & ATCC 96988 & Exudate of Quercus sp. & The Netherlands & 14 & 1 \\
\hline CBS 432 & ATCC 96965 & Unknown & Unknown & 14 & 1 \\
\hline CBS 5829 & ATCC 96966 & Mor soil & Denmark & 14 & 2 \\
\hline INMIV 11/21 & ATCC 96976 & Poplar tree & Kiev, Ukraine & 14 & 3 \\
\hline INMIV 544 & ATCC 96979 & Aspen leaves & Kiev, Ukraine & 14 & 4 \\
\hline CECT 10176 & ATCC 96989 & Noctua pronubula (adult) & Spain & 25 & 2 \\
\hline CECT 10178 & ATCC 96972 & Noctua pronubula (adult) & Spain & 25 & 1 \\
\hline CECT 10308 & ATCC 96967 & Frass in Quercus lusitanus & Spain & 25 & 1 \\
\hline CECT 10329 & АТСС 96969 & Frass in Quercus ilex & Spain & 25 & 5 \\
\hline VKM Y-2472 & ATCC 96975 & Peat & Moscow, Russia & 15 & 1 \\
\hline N7 & ATCC 96885 & Exudate of Quercus robur & St. Petersburg, Russia & 15 & 1 \\
\hline N8 & ATCC 96987 & Exudate of Quercus robur & Moscow, Russia & 15 & 1 \\
\hline N9 & ATCC 96886 & Exudate of Quercus sp. & Tashkent, Uzbekistan & 15 & 6 \\
\hline N11 & ATCC 96985 & Exudate of Quercus robur & Novgorod, Russia & 15 & 5 \\
\hline N12 & ATCC 96978 & Exudate of Quercus sp. & Lenkoran, Azerbaijan & 15 & 1 \\
\hline N13 & ATCC 96986 & Exudate of Quercus robur & Moscow, Russia & 15 & 1 \\
\hline N15 & ATCC 96982 & Exudate of Quercus robur & Moscow, Russia & 15 & 1 \\
\hline N16 & ATCC 96983 & Exudate of Quercus robur & Moscow, Russia & 15 & 1 \\
\hline N17 & ATCC 96981 & Exudate of Quercus robur & Tartastan, Russia & 15 & 1 \\
\hline $\mathrm{N} 18$ & ATCC 96984 & Exudate of Quercus robur & Efremov, Russia & 15 & 1 \\
\hline $\mathrm{N} 25$ & ATCC 96973 & Exudate of Quercus robur & Estonia & 17 & 1 \\
\hline N34 & ATCC 96980 & Exudate of Quercus robur & Voronezh, Russia & 15 & 1 \\
\hline N36 & ATCC 96990 & Exudate of Quercus sp. & Lithuania & 24 & 1 \\
\hline $\mathrm{N} 40$ & ATCC 96974 & Exudate of Quercus sp. & Yalta, Ukraine & This study & 1 \\
\hline N41 & ATCC 96977 & Exudate of Quercus sp. & Yalta, Ukraine & This study & 1 \\
\hline ALKO 2638 & ATCC 96968 & Exudate of Quercus sp. & Finland & 22 & 1 \\
\hline ALKO 2639 & ATCC 96971 & Exudate of Quercus sp. & Finland & 22 & 1 \\
\hline DBVPG 1373 & ATCC 96970 & Soil & The Netherlands & 22 & 1 \\
\hline \multicolumn{6}{|l|}{$\mathrm{FE}$ isolates } \\
\hline IFO 1804 & & Bark & Japan & 23 & 9 \\
\hline IFO 1805 & & Bark & Japan & 23 & 9 \\
\hline $\mathrm{N} 42$ & & Exudate of Quercus mongolica & Vladivostok, Russia & 20 & 7 \\
\hline $\mathrm{N} 43$ & & Exudate of Quercus mongolica & $\begin{array}{l}\text { Cape Peschanyi, Vladivostok, } \\
\text { Russia }\end{array}$ & 20 & 8 \\
\hline N44 & & Exudate of Quercus mongolica & Ternei, Russia & 20 & 7 \\
\hline N45 & & Exudate of Quercus mongolica & Ternei, Russia & 20 & 9 \\
\hline N46 & & Exudate of Quercus mongolica & Sikhote-Alinsky Reserve, Russia & 20 & 7 \\
\hline N47 & & Exudate of Quercus mongolica & Alinsky Reserve, Russia & 20 & 9 \\
\hline $\mathrm{N} 48$ & & Exudate of Quercus mongolica & $\begin{array}{l}\text { v. Rjazanovka, Khazansky } \\
\text { District, Russia }\end{array}$ & 20 & 9 \\
\hline N49 & & Exudate of Quercus dentata & $\begin{array}{l}\text { v. Rjazanovka, Khazansky } \\
\text { District, Russia }\end{array}$ & 20 & 9 \\
\hline N50 & & Exudate of Quercus mongolica & Chajka, Vladivostok, Russia & 20 & 7 \\
\hline
\end{tabular}

${ }^{a}$ ATCC, American Type Culture Collection, Rockville, Md.; CBS, Centraalbureau voor Schimmelcultures, Delft, The Netherlands; INMIV, Institute for Microbiology and Virology of the Ukraine Academy of Sciences, Kiev, Ukraine; CECT, Coleccion Española de Cultivos Tipo, Valencia, Spain; VKM, All-Russian Collection of Microorganisms, Moscow, Russia; ALKO, Research Laboratories of the Finnish State Alcohol Company, Helsinki, Finland; DBVPG, Industrial Yeasts Collection of the Department of Plant Biology, University of Perugia, Perugia, Italy; IFO, Institute for Fermentation, Osaka, Japan. Strains whose designations begin with N were obtained from the collection of G. I. Naumov. Additional FE isolates have been deposited in the American Type Culture Collection.

STRUC (30) was used to estimate the probability of the table. Pairwise genetic similarities among multilocus electrophoretic types (ETs) were estimated by calculating simple matching coefficients (31); genetic distances were calculated by subtracting these coefficients from 1 . The program MEGA (9) was used to produce an unweighted pair group with mathematical average (UPGMA) dendrogram from the matrix of pairwise genetic distances.

\section{RESULTS}

Genetic variability among all of the isolates. Nine different multilocus ETs were observed among the $39 \mathrm{~S}$. paradoxus isolates examined. Table 1 shows the ET to which each isolate belonged. No ETs were shared by the EU isolates and the FE isolates. Six ETs (designated ETs 1 through 6) were identified in the sample containing the $28 \mathrm{EU}$ isolates, and three ETs (designated ETs 7 through 9) were identified in the sample of FE isolates. The number of alleles and gene diversity (26) at each locus for the full data set, including all $39 \mathrm{EU}$ and FE isolates, are shown in Table 2. Although the proportion of polymorphic loci observed across all isolates was relatively high (0.66), most of the variation observed was due to differences between the EU and FE isolate collections in allelic composition at the six variable loci. Similarly, although several nonrandom allelic associations between pairs of loci were suggested by the results of an inspection of the full data set for haplotypes (data not shown), these associations also were attributable to four apparently fixed or nearly fixed allelic differences between the isolate collections. We describe the allelic compositions of the EU and FE isolate collections separately below. 
TABLE 2. Genetic variability at nine enzyme loci for 39 isolates of S. paradoxus

\begin{tabular}{|c|c|c|c|c|c|c|}
\hline \multirow{2}{*}{ Enzyme } & \multicolumn{2}{|c|}{$\begin{array}{c}\text { EU and FE } \\
\text { isolates }(n=39)\end{array}$} & \multicolumn{2}{|c|}{$\begin{array}{l}\text { EU isolates alone } \\
\quad(n=28)\end{array}$} & \multicolumn{2}{|c|}{$\begin{array}{c}\mathrm{FE} \text { isolates alone } \\
\quad(n=11)\end{array}$} \\
\hline & $\begin{array}{l}\text { No. of } \\
\text { alleles }\end{array}$ & $\begin{array}{l}\text { Gene } \\
\text { diversity }\end{array}$ & $\begin{array}{l}\text { No. of } \\
\text { alleles }\end{array}$ & $\begin{array}{c}\text { Gene } \\
\text { diversity }\end{array}$ & $\begin{array}{l}\text { No. of } \\
\text { alleles }\end{array}$ & $\begin{array}{c}\text { Gene } \\
\text { diversity }\end{array}$ \\
\hline $\mathrm{ADH}$ & 1 & 0 & 1 & 0 & 1 & 0 \\
\hline ARK & 1 & 0 & 1 & 0 & 1 & 0 \\
\hline G6PDH & 2 & 0.22 & 1 & 0 & 2 & 0.54 \\
\hline GPI & 2 & 0.18 & 2 & 0.20 & 2 & 0.19 \\
\hline IDH & 2 & 0.39 & 1 & 0 & 1 & 0 \\
\hline $\mathrm{LDH}$ & 2 & 0.39 & 1 & 0 & 1 & 0 \\
\hline $\mathrm{MDH}$ & 1 & 0 & 1 & 0 & 1 & 0 \\
\hline MPI & 3 & 0.43 & 2 & 0.07 & 1 & 0 \\
\hline PGM & 3 & 0.48 & 3 & 0.20 & 1 & 0 \\
\hline Mean & 1.89 & 0.23 & 1.44 & 0.05 & 1.22 & 0.08 \\
\hline
\end{tabular}

EU isolates. The number of alleles and gene diversity at each locus for the EU isolate collection are shown in Table 2. Six of the nine enzymes examined (LDH, IDH, G6PDH, ADH, $\mathrm{MDH}$, and $\mathrm{ARK}$ ) were not variable in the EU isolate collection. Three electrophoretic phenotypes were identified for GPI activity. A common fast allele, Gpi-1, was observed in 25 isolates; a slow allele, Gpi-2, was observed in 2 isolates; and 1 isolate, INMIV 544, carried both allele Gpi-1 and allele Gpi-2, suggesting that duplication of the Gpi gene had occurred. A fast MPI allele, Mpi-1, was present in one isolate; all other isolates harbored the slow Mpi-2 allele. PGM migrated cathodally in all of the isolates studied (both the EU isolates and the FE isolates); staining for PGM revealed two bands in all of the isolates except CECT 10176 and CBS 5829, in which the upper band was absent. A fast cathodally migrating Pgm allele was observed in isolate INMIV 11/21.

FE isolates. The number of alleles and gene diversity at each locus for the FE isolate collection are shown in Table 2 . Three enzymes, ADH, ARK, and MDH, were detected in the same allelic form in the FE isolate collection and in the EU isolate collection and were not variable. The slow GPI allele Gpi-2, which had been observed in two EU isolates, was present in one FE isolate; all of the other isolates harbored the most common allele, Gpi-1. For G6PDH, six isolates exhibited the common electromorph, and five isolates (N42, N43, N45, N47, and N50) had a variant phenotype with two bands that was unique to the $\mathrm{FE}$ isolate collection. A PGM variant observed in all 11 isolates of the FE isolate collection was present in only one EU isolate, INMIV 11/21. The remaining three enzymes (IDH, LDH, MPI) were monomorphic within the FE isolate collection, but were detected as alleles that were different from the alleles observed in the EU isolate collection.

Genetic differentiation between the $\mathrm{EU}$ and FE isolates. The FE and EU isolate collections differed significantly in allelic composition at the following five loci: G6pdh, Pgm, Idh, $L d h$, and $M p i(P \ll 0.001$ in every case, as determined by two-tailed Fisher exact tests). Combining probability estimates for the individual tests at all six informative loci (G6pdh, Pgm, Idh, $L d h, M p i$, and $G p i$ ) by the method of Fisher (4) gave a highly significant $\chi^{2}(P<0.001$; df $=12)$, which supported the conclusion that the two isolate collections represent genetically distinct subpopulations. (The method of combining probabilities relies on the independence of the individual significance tests. The independence of the loci examined in this study could in principle be supported by nonsignificant linkage disequilibria within each population; however, insufficient varia-

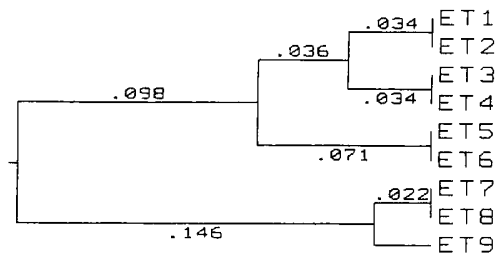

$$
\ominus \Gamma \cdot \theta 1
$$

FIG. 1. UPGMA dendrogram based on pairwise genetic distances (see Materiais and Methods) among the nine ETs observed in this study. ETs 1 through 6 are unique to the EU isolates; ETs 7 through 9 are unique to the FE isolates.

tion was observed for meaningful tests of within-population linkage disequilibrium.)

Figure 1 is a UPGMA dendrogram illustrating the genetic relationships among the nine ETs observed in this study. As expected given the genetic differences described above, ETs 7 through 9, which represented the entire FE isolate collection and were unique to it, clearly form a group distinct from the group made up of ETs 1 through 6, which were observed solely in EU isolates.

\section{DISCUSSION}

The allozyme data presented here indicate that the EU and $\mathrm{FE}$ isolates belong to genetically distinct geographical populations of the biological species $S$. paradoxus, a European population (including one isolate from Uzbekistan, isolate N9) and a Far East Asian population. The EU isolates differed almost completely from the FE isolates in allelic composition at four enzyme loci ( $I d h, L d h, M p i$, and $P g m$ ) and differed significantly in allele frequencies at a fifth locus, G6pdh.

In previous genetic hybridization studies we have noted that the viability of ascospores derived from crosses within the biological species $S$. paradoxus depended on the geographic origin of the parent isolates crossed. Fifty $S$. paradoxus isolates from a number of sites in Europe exhibited generally high ascospore viability $(67.1 \% \pm 1.1 \%)$ in intraspecific crosses with European tester strain CBS 5829 isolated in Denmark (14-18, $22,24,25)$, whereas 12 isolates from the Russian Far East and 2 isolates from Japan exhibited markedly lower ascospore viability $(42.3 \% \pm 2.3 \%)$ in crosses with the same tester strain $(16,20,23)$. Taken together with the data on genetic variability presented here, these data suggest that geographically separated populations of $S$. paradoxus could represent early stages in allopatric speciation. Further research examining the fertility of crosses among isolates from the same and different geographical regions will be necessary to test this possibility.

Although in our study we examined a small number of enzymes, the results suggest that genetic variation within the European and Far East Asian populations of $S$. paradoxus is relatively low. In contrast, other studies have shown that the cultivated yeasts $S$. cerevisiae, $S$. bayanus, and $S$. pastorianus are very polymorphic for many enzymes $(10,32,39)$. For example, among $18 \mathrm{~S}$. cerevisiae isolates taken from stock cultures of wine yeasts, no two yeasts had identical electrophoretic patterns for five enzymes studied (32). It is likely that the low genetic variation within the two wild $S$. paradoxus populations studied here is related to the degree of inbreeding. No estimates of selfing rates in wild yeasts are available. However, wild isolates of $S$. paradoxus are homothallic and readily produce monosporic diploid clones in the laboratory through mating type switching, and thus a high level of selfing in natural populations seems likely. A number of evolutionary processes 
can account for reduction in neutral genetic variability within highly inbred populations, including genetic hitchhiking (6), background selection against deleterious mutations (2), and genetic drift associated with decreases in effective population size (29). Future research in which higher-resolution molecular techniques are used to characterize genetic variation in $S$. paradoxus may provide important insight into the extent of selfing in wild yeast populations and its role in shaping genetic variation.

This is the first study to document geographical genetic differentiation within a Saccharomyces species classified according to the biological species concept. The results suggest that evolutionary genetic studies of wild Saccharomyces populations are both feasible and likely to be of general interest. Indeed, such studies may provide the evolutionary context essential for a fuller understanding of important phenomena (e.g., transposable elements, mating type switching) first discovered and studied in the classical and molecular genetics of S. cerevisiae.

\section{ACKNOWLEDGMENTS}

We thank Richard Lenski for his interest in this work, and we are grateful to Brendan Bohannan, Shenandoah Oden, and Valeria Souza for technical advice and assistance in the performance of cellulose acetate electrophoresis.

This research was supported by NSF grant BIR-9120006 to the Center for Microbial Ecology, Michigan State University.

\section{REFERENCES}

1. Adjiri, A., R. Chanet, C. Mezard, and F. Fabre. 1994. Sequence comparison of the ARG4 chromosomal regions from the two related yeasts, Saccharomyces cerevisiae and Saccharomyces douglassii. Yeast 10:309-317.

2. Charlesworth, B., M. T. Morgan, and D. Charlesworth. 1993. The effect of deleterious mutations on neutral molecular variation. Genetics 134:12891303 .

3. Engels, W. 1988. FISH6, version 1.001. University of Wisconsin Genetics Department, Madison.

4. Fisher, R. A. 1958. Statistical methods for research workers. Oliver and Boyd, Edinburgh, United Kingdom.

5. Hebert, P. D. N., and M. J. Beaton. 1993. Methodologies for allozyme analysis using cellulose acetate electrophoresis. University of Guelph, Guelph, Ontario, Canada.

6. Hedrick, P. W. 1980. Hitchhiking: a comparison of linkage and partial selfing. Genetics 94:791-808.

7. Kaneko, Y., and I. Banno. 1991. Reexamination of Saccharomyces bayanus isolates by DNA-DNA hybridization and electrophoretic karyotyping. IFO Res. Commun. 15:30-41.

8. Kulkarni, R. K., C. D. Kamerath, and K. L. Allred. 1986. Genetic diversity between isolates of Pleurotus ostreatus as revealed by isozyme analysis, $\mathrm{p}$ 171-181. In P. J. Wuest, D. J. Royse, and R. B. Beelman (ed.), Developments in crop sciences, vol. 10. Cultivating edible fungi. Elsevier Press, Amsterdam, The Netherlands.

9. Kumar, S., K. Tamura, and M. Nei. 1993. MEGA: molecular evolutionary genetics analysis, version 1.0. The Pennsylvania State University, University Park.

10. Lewicka, K., M. Mallie, and J.-M. Bastide. 1995. Genetic variability in the Saccharomyces sensu stricto complex revealed by multilocus enzyme electrophoresis. Int. J. Syst. Bacteriol. 45:538-543.

11. Li, G.-Y., G.-L. Tian, P. P. Slonimski, and C. J. Herbert. 1996. The $C B P 2$ gene from Saccharomyces douglassii is a functional homologue of the Saccharomyces cerevisae gene and is essential for respiratory growth in the presence of a wild-type (intron-containing) mitochondrial genome. Mol. Gen. Genet. 250:316-322.

12. Mayr, E. 1942. Systematics and the origin of species. Columbia University Press, New York, N.Y

13. Naumov, G. I. 1980. The biological species Saccharomyces terrestis. Dokl. Biol. Sci. (Engl. Transl. Dokl. Akad. Nauk SSSR) 249:1248-1250.
14. Naumov, G. I. 1986. Genetic differentiation and ecology of the yeast Saccharomyces paradoxus Batschinskaia. Dokl. Biol. Sci. (Engl. Transl. Dokl. Akad. Nauk SSSR) 289-291:213-216.

15. Naumov, G. I. 1987. Genetic basis for classification and identification of the ascomycetous yeasts. Stud. Mycol. 30:469-475.

16. Naumov, G. I. 1988. A hybridological study of the yeast Saccharomyces from the expedition collection of V. I. Kudriavzev (during 1934 and 1936). Mikol. Fitopatol. 22:295-301. (In Russian.)

17. Naumov, G. I. 1989. Occurrence of Saccharomyces paradoxus in Estonia Eesti NSV Tead. Akad. Toim. Biol. 39:9-12. (In Russian.)

18. Naumov, G. I. Genetic identification of biological species in the Saccharomyces sensu stricto complex. J. Int. Microbiol., in press.

19. Naumov, G. I., and E. S. Naumova. 1990. Saccharomyces douglasii: a synonym of $S$. paradoxus as defined by hybrid analysis. Dokl. Biol. Sci. (Engl. Transl. Dokl. Akad. Nauk SSSR) 311:208-209.

20. Naumov, G. I., E. S. Naumova, Z. M. Azbukina, M. Korhola, and C. Gaillardin. 1993. Genetic and karyotypic identification of Saccharomyces sensu stricto yeasts from Far East Asia. Cryptogam. Mycol. 14:85-93.

21. Naumov, G. I., E. S. Naumova, A. N. Hagler, L. C. Mendonça-Hagler, and E. J. Louis. 1995. A new genetically isolated population of the Saccharomyces sensu stricto complex from Brazil. Antonie van Leeuwenhoek 67:351-355.

22. Naumov, G. I., E. S. Naumova, and M. Korhola. 1992. Genetic identification of natural Saccharomyces sensu stricto yeasts from Finland, Holland and Slovakia. Antonie van Leeuwenhoek 61:237-243.

23. Naumov, G. I., E. S. Naumova, and E. J. Louis. 1995. Two new genetically isolated populations of the Saccharomyces sensu stricto complex from Japan. J. Gen. Appl. Microbiol. 41:499-505.

24. Naumov, G. I., and T. A. Nikonenko. 1988. New isolate of Saccharomyces paradoxus yeasts from oak exudates. Biol. Nauki (Moscow) 7:84-87. (In Russian.)

25. Naumov, G. I., E. S. Naumova, and E. D. Sancho. 1994. Sibling species of the Saccharomyces sensu stricto complex in Spain. Microbiol. SEM 10:403-412.

26. Nei, M. 1987. Molecular evolutionary genetics. Columbia University Press, New York, N.Y.

27. Perkins, D. D., B. C. Turner, and E. G. Barry. 1976. Strains of Neurospora collected from nature. Evolution 30:281-313.

28. Petersen, R. H. 1995 . There's more to a mushroom than meets the eye: mating studies in the Agaricales. Mycologia 87:1-17.

29. Pollak, E. 1987. On the theory of partially inbreeding finite populations. I. Partial selfing. Genetics 117:353-360.

30. Raymond, M., and F. Rousset. 1995. GENEPOP (ver. 1.2): a population genetics software for exact tests and ecumenicism. J. Hered. 86:248-249.

31. Selander, R. K., D. A. Caugant, H. Ochman, J. M. Musser, M. N. Gilmour, and T. S. Whittam. 1986. Methods of multilocus enzyme electrophoresis for bacterial population genetics and systematics. Appl. Environ. Microbiol. 51:873-884.

32. Subden, R. E., D. Irwin, J. D. Cunningham, and A. G. Meiering. 1982. Wine yeast isozymes. I. Genetic differences in stock cultures. Can. J. Microbiol. 28:1047-1050.

33. Vaughan Martini, A. 1989. Saccharomyces paradoxus comb. nov., a newly separated species of the Saccharomyces sensu stricto complex based upon nDNA/nDNA homologies. Syst. Appl. Microbiol. 12:179-182.

34. Vaughan Martini, A., and C. P. Kurtzman. 1985. Deoxyribonucleic acid relatedness among species of the genus Saccharomyces sensu stricto. Int. J. Syst. Bacteriol. 35:508-511.

35. Vaughan Martini, A., and A. Martini. 1987. Three newly delimited species of Saccharomyces sensu stricto. Antonie van Leeuwenhoek 53:77-84.

36. Vilgalys, R. 1991. Speciation and species concepts in the Collybia dryophila complex. Mycologia 83:758-773.

37. Vilgalys, R., A. Smith, B. L. Sun, and O. K. Miller, Jr. 1993. Intersterility groups in the Pleurotus ostreatus complex from the continental United States and adjacent Canada. Can. J. Bot. 71:113-128.

38. Yamada, Y., K. Mikata, and I. Banno. 1993. Reidentification of 121 strains of the genus Saccharomyces. Bull. Jpn. Fed. Culture Collect. 9:95-119. (In Japanese.)

39. Yamazaki, M., S. Goto, and K. Komagata. 1983. An electrophoretic comparison of the enzymes of Saccharomyces yeasts. J. Gen. Appl. Microbiol. 29:305-318.

40. Zervakis, G., and J. Labarère. 1992. Taxonomic relationships within the fungal genus Pleurotus as defined by isoelectric focusing analysis of enzyme patterns. J. Gen. Microbiol. 138:635-645.

41. Zervakis, G., J. Sourdis, and C. Balis. 1994. Genetic variability and systematics of eleven Pleurotus species based on isozyme analysis. Mycol. Res 98:329-341. 